\begin{tabular}{ll}
\hline POLITEIA & POLITEIA: Jurnal Ilmu Politik \\
& Politeia, 14 (1) (2022): 42-54 \\
ISSN (Print), ISSN (Online) \\
Available online https://jurnal.usu.ac.id/index.php/politeia
\end{tabular}

\title{
Politik Pembangunan Desa dalam Program Saemaul Undong di Desa Ponjong, Kabupaten Gunung Kidul, Yogyakarta
}

\author{
Yohansen Wyckliffe Gultom* \\ Magister Ilmu Politik, Fakultas Ilmu Sosial dan Ilmu Politik, Universitas Sumatera Utara, \\ Sumatera Utara, Indonesia, 20155
}

Submitted : 29 Juli 2021 Revision : 18 Desember 2021 Accepted : 10 Januari 2022

\begin{abstract}
Abstrak
Program Saemaul Undong yang pernah diterapkan di era Presiden Park Chung Hee 1963-1979, telah menjadi gerakan global di Asia dan Afrika. Melalui Saemaul Globalization Foundation (SGF) Korea Selatan, program Saemaul Undong telah diterapkan di beberapa desa di Indonesia, salah satunya Desa Ponjong, Kabupaten Gunung Kidul Yogyakarta. Penerapannya dipadukan dengan Undang-Undang Desa No. 6 tahun 2014. Akibatnya, di desa Ponjong, peran BUMDes bergerak semakin optimal, dengan penguatan pengorganisasian desa, penentuan produk unggulan; kandang sapi komunal dan gedung serbaguna. UU Desa No. 6 pasal 91 sebenarnya membuka ruang bagi desa di Indonesia untuk meniru pola itu, dengan bekerja sama dengan pihak ke-3 dan strategi dalam program Saemaul Undong di Desa Ponjong bisa menjadi opsi bagi desa di Indonesia dalammemperluas kerjasamanya dengan pihak ke-3. Metodologi di dalam studi ini, dilakukan dengan pendekatan aktor dan sistem politik. Metode yang digunakan dalam menganalisis data menggunakan metode deskriptif kualitatif, untuk menemukan gambaran yang utuh antara peran aktor dan sistem, serta untuk menemukan berbagai program yang terdapat di dalam pelaksanaan program Saemaul Undong di Desa Ponjong Kabupaten Gunung Kidul, Yogyakarta tahun 2015-2019. Metode pengumpulan data, dengan menggunakan teknik wawancara mendalam dan observasi langsung ke lapangan, serta merujuk pada studi pustaka yang ditemukan dari referensi sekunder dan data yang ditemukan di Desa Ponjong, Kabupaten Gunung Kidul, Yogyakarta.
\end{abstract}

Kata Kunci: Pembangunan Desa, Saemaul Undong, UU Desa No. 6 tahun 2014

Abstract

The Saemaul Undong program, which was implemented in the President Park Chung Hee era from 1963 to 1979, has become a global movement in Asia and Africa. Through South Korea's Saemaul Globalization Foundation (SGF), the Saemaul Undong program has been implemented in several villages in Indonesia, one of them is Ponjong Village, Gunung Kidul Regency, Yogyakarta. Its application is combined with Village Law no. 6 of 2014. As a result, in Ponjong village, the role of BUMDes moves more optimally, by strengthening village organization, determining superior products; communal cowshed and multipurpose building. Village Law no. 6 chapter 91 actually opens space for villages in Indonesia to imitate that pattern, by cooperating with 3rd parties and the strategy in the Saemaul Undong program in Ponjong Village can be an option for villages in Indonesia in expanding their cooperation with 3rd parties. The methodology in this study is carried out using an actor and political system approach. The method used in analyzing the data by descriptive qualitative methods, to find a complete picture between the roles of actors and the system, as well as to find various programs contained in the implementation of the Saemaul Undong program in Ponjong Village, Gunung Kidul Regency, Yogyakarta in 2015-2019. Data collection methods, using in-depth interviews and direct observation in the field, and referring to literature studies found from secondary references and data in Ponjong Village, Gunung Kidul Regency, Yogyakarta.

Keywords: Rural Development, Saemaul Undong, Village Law No.6/2014

How to Cite:Gultom, Y W. (2022).Politik Pembangunan Desa dalam Program Saemaul Undong di Desa Ponjong, Kabupaten Gunung Kidul, Yogyakarta, Politeia: Jurnal Ilmu Politik, 14 (1): 42-54.

*Corresponding author:

E-mail: Gultomjohansen@yahoo.com 


\section{PENDAHULUAN}

Program Saemaul Undong atau dalam makna harfiah: Saemaul (Pedesaan Baru) dan Undong (Gerakan) atau dapat pula bermakna sebagai gerakan desa baru (new village movement) merupakan suatu program pembangunan yang memajukan Korea Selatan di era Presiden Park Chung Hee, sejak tahun 1963-1979. Meski sempat mengalami krisis di berbagai lini, pasca keterpurukan akibat konflik di Semenanjung Korea (proxy war) membuat PDB (Produk Domestik Bruto) Korea Selatan hanya berada di kisaran US\$ 100 atau sekitar Rp. $\quad 1.300 .000$ (kurs 13.000/1\$). Untungnya, melalui Program Saemaul Undong, progres kemajuan Korea Selatan kian berkembang pesat, bahkan menjadikan Korea Selatan sebagai The Asian Newly Industrialized Countries (NICs) bersama Hongkong, Singapura dan Taiwan dekade 19701980 (Gultom, 2019:6-7).

Keberhasilan Chung Hee, dimulai dengan beberapa hal; pertama, penanaman filosofi pembangunan kepada 33.267 desa melalui pembentukan 680.000 training camps, lewat penyamaan visi untuk keluar dari kemiskinan absolut, reformasi spiritual dengan kesadaran masyarakat yang setara dengan masyarakat global, penanaman semangat sebagai gerakan untuk bangkit pasca PD (Perang Dunia) II, berfokus pada pembangunan masyarakat lokal dan agrikultural dan penanaman etika kerja secara kolektif bagi petani. Selain itu, terdapat program prioritas bertahap dengan gerak progresif dan konstruktif menuju industrialisasi dengan terlebih dahulu melakukan penguatan masyarakat lokal. Selain itu, Chung
Hee juga membangun sebuah sistem yang saling mengawasi dari pusat hingga ke tingkat desa sehingga program Saemaul Undong bisa terlaksana dengan baik (Gultom, 2021:24-26).

Di Indonesia, program Saemaul Undong sesungguhnya telah berlangsung di empat desa di Indonesia yaitu; Desa Tanjung Wangi di Subang, Jawa Barat, Desa Sumber Mulyo di Bantul, Yogyakarta, Desa Bleberan dan Desa Ponjong di Kabupaten Gunung Kidul Yogyakarta. Meskipun demikian, berkat adanya perbedaan suprastruktur dan infrastruktur politik antara Indonesia dan Korea Selatan, tentu perealisasian Program Saemaul Undong yang terdapat di Korea Selatan era Presiden Chung Hee degan yang diterapkan di Desa Ponjong berbeda dalam model, aktor dan sistemnya.

Namun, jika melihat regulasi Indonesia berdasarkan UndangUndang Desa No. 6 tahun 2014 pasal 1 ayat 1 , tentu memberikan ruang bagi desa untuk mengatur dan mengurus urusan pemerintahan, kepentingan masyarakat setempat berdasarkan prakarsa masyarakat yang diakui dan dihormati dalam sistem pemerintahan Indonesia. Selain itu, Undang-Undang Desa No. 6 tahun 2014 pasal 91 juga menjelaskan bahwa, desa dapat mengadakan kerjasama dengan desa lain dan/atau kerja sama dengan pihak ketiga untuk meningkatkan penyelenggaraan pemerintah desa, pembangunan, pemberdayaan dan pembinaan masyarakat di desa yang bersangkutan. Berdasarkan regulasi tentang desa yang berlaku di Indonesia tersebut, tentu ruang untuk melakukan kerjasama dengan pihak 
ketiga menjadi suatu hal yang patut untuk dilakukan semaksimal mungkin demi kemajuan desa.

Upaya internalisasi program Saemaul Undong sudah berlangsung, tidak hanya di Indonesia, namun mulai di globalkan ke beberapa negara berkembang di dunia sebagai upaya memperluas pengaruh Saemaul Undong sebagai program pembangunan desa yang dinilai memiliki peran besar dalam kemajuan Korea Selatan. YSGF (Yayasan Saemaul Globalization Foundation) yang berkantor pusat di Korea Selatan, menjadi Yayasan yang mengevaluasi, mengawasi dan mendampingi pelaksanaan programprogram pembangunan desa yang menjalankan program Saemaul Undong, seperti di negara; Kongo, Sri Lanka, Mongolia, Rusia, Cina, Vietnam dan termasuk di Indonesia melalui yayasan-yayasan yang terdapat di masing-masing negara dan di desa binaan (Kyungwon University Saemaul Academy, 2008:46).

Secara khusus di Indonesia, program Saemaul Undong mulai diinisiasi perencanaannya sejak tahun 2001 ketika Provinsi GyeongsangbukDo, Korea Selatan menjalin kerjasama sister provincedengan delegasi Provinsi Yogyakarta. Baru di tahun 2005, Gubernur Gyeongsangbuk-Do bernama Kim Kwan Yong menandatangani kesepakatan dengan Sri Sultan Hamengkubuwono X, selaku Gubernur DIY (Daerah Istimewa Yogyakarta) menyepakati perjanjian berjudul: Saemaul Undong Program in the Sister Province Cooperation Frame Work, dengan persiapan kerjasama diteruskan hingga tahun 2014. Poin-poin penting yang disepakati dalam perjanjian tersebut, diantaranya; 1. Kedua provinsi membuat kesepakatan merealisasikan Saemaul Undong di masing-masing desa di daerah percontohan yang ditetapkan. 2 . Proyek percontohan akan dibuat di Yogyakarta dan sekitarnya. 3. Meningkatkan kerjasama untuk membangun kapasitas pembangunan pedesaan (Royani, 2018:8-9).

Cara atau metode yang dilaksanakan di daerah-daerah di kawasan Yogyakarta dan sekitarnya tentu disesuaikan dengan keadaan geografis dan lingkungan sosial penduduk dengan konsep yang berbeda dengan apa yang dijalankan di tahun 1970-an di Korea Selatan.

Inisiatif awal yang semula bergerak dalam program lintas provinsi antara Yogyakarta dengan Gyeongsangbuk-Do, Korea Selatan berkembang menjadi aktivitas $G$ to G(Government to Government) antara pemerintah Indonesia dengan Korea Selatan ketika Menteri PDTT (Pembangunan Daerah Tertinggal dan Trasmigrasi) Indonesia, Marwan Jatar melakukan kunjungan ke Korea Selatan pada 24 Oktober 2015, kemudian dibuatlah kesepakatan Network Village (Invil) sebagai forum untuk membangun konsep Saemaul Undong di Indonesia, dengan beberapa desa percontohan di kawasan, Bantul, Gunung Kidul, Garut, Sukabumi, Bondowoso, Situbondo dan Madura dengan konsep pelaksanaan Saemaul Undong dan desa berbasis IT (Internet dan Teknologi). Untuk membantu perealisasian program, dilibatkan pula peran Kementrian Pertanian Korea Selatan, Lee Dong Phil yang sempat menawarkan investasi bagi 
Indonesia untuk membangun kawasan perbatasan dan peningkatan kapasistas produksi dan pertanian desa di NTB, NTT, Kalimantan dan Papua sebagai upaya untuk mengglobalkan program Saemaul Undong(Primus, 2019).

Kesepakatan antara Indonesia dengan Korea Selatan ini kemudian menghasilkan Permendes (Peraturan Menteri Desa) Pembangunan Daerah Tertinggal dan Transmigrasi atau Permendes (PDTT) No. 4 tahun 2015 tentang Pendirian, Pengurusan dan Pengelolaan dan Pembubaran BUMDes (Badan Usaha Milik Desa) yang ditetapkan pada 13 Februrari 2015. Tentu regulasi ini, mengacu ke UU (Undang-Undang) Desa No. 6 tahun 2014.

Berdirinya YGSI (Yayasan Globalisasi Saemaul Indonesia), yang berkantor pusat di Fakultas Filsafat UGM (Universitas Gadjah Mada) menjadi kantor perwakilan nasional yang berkoordinasi dengan YSGF (Yayasan Saemaul Globalization Foundation) pusat di Korea Selatan dan menjadi tempat perwakilan untuk mengkoordinir pelaksanaan program Saemaul Undongdi kawasan; Bantul, Gunung Kidul, Garut, Sukabumi, Bondowoso, Situbondo dan Madura.

Besarnya atensi internasional dari negara gingseng, Korea Selatan, serta adanya atensi pusat (Kementrian Pembangunan Daerah Tertinggal dan Transmigrasi) dan Provinsi DIY (Daerah Istimewa Yogyakarta) membuat pelaksanaan Program Saemaul Undonglayak untuk diteliti, terlebih karena Undang-Undang Desa No. 6 tahun 2014, pasal 1 dan pasal 91 juga menjadi pintu masuk bagi desa di Indonesia untuk mengembangkan potensinya dengan pihak ketiga.
Sehingga, akan sangat baik jika penelitian ini menjadi pembelajaran bagi desa-desa lain di Indonesia untuk mengembangkan kawasannya berdasarkan studi komparatif di salah satu desa yang ada di Indonesia, khususnya dalam hal ini, di Desa Ponjong Kabupaten Gunung Kidul, Yogyakarta sebagai salah satu desa yang melaksanakan Program Saemaul Undong.Dengan demikian, ditemukan suatu model yang baik dan layak ditiru untuk mengembangkan desa di Indonesia.

Itu sebabnya, penelitian ini ingin mengobservasi, bagaimana realisasi Politik Pembangunan Desa dalam Program Saemaul Undong di Desa Ponjong, Kabupaten Gunung Kidul Yogyakarta berdasarkan pendekatan aktor dan sistem dari pelaksanaan program Saemaul Undong tersebut. Kemudian, penelitian ini ingin melihat program-program apa saja yang dihasilkan dengan dijalankannya program Saemaul Undong di Desa Ponjong selaku desa percontohan yang melaksanakan program Saemaul Undong dimulai sejak tahun 2016 hingga tahun 2019, sehingga berbagai desa di Indonesia bisa memiliki kerangka acuan di dalam mengembangkan potensi desanya.

\section{METODE PENELITIAN}

Studi ini dilakukan dengan pendekatan aktor dan sistem politik. Metode yang digunakan dalam menganalisis data menggunakan metode deskriptif kualitatif, untuk menemukan gambaran yang utuh antara peran aktor dan sistem, serta menemukan berbagai program yang terdapat di dalam pelaksanaan program Saemaul Undong di Desa 
Ponjong Kabupaten Gunung Kidul, Yogyakarta sejak tahun 2015-2019. Metode pengumpulan data, dengan menggunakan teknik wawancara mendalam dan observasi langsung ke lapangan, serta merujuk pada studi pustaka yang ditemukan dari referensi sekunder dan data yang ditemukan langsung di lapangan, sesuai berlangsungnya program di Desa Ponjong, Kabupaten Gunung Kidul, Yogyakarta.

\section{HASIL DAN PEMBAHASAN}

Pasca berlangsungnya

kesepakatan $G$ to $G$ antara Korea Selatan dan Indonesia, maka YSGF (Yayasan Saemaul Globalization Foundation) menjalin kerjasama dengan YSGI (Yayasan Saemaul Globalisasi Indonesia) yang berada di Fakultas Filsafat Universitas Gadjha Mada (UGM), di depan ruang Trisakti. Sehingga, koordinasi antara desa-desa binaan di desa; Ponjong, Bleberan dan Sumber Mulyo serta Desa Tanjung Wangi dalam menjalankan program Saemaul Undong akan dikoordinir YSGI (Yayasan Saemaul Globalisasi Indonesia).

Sebelum menjalankan kinerjanya, YSGI (Yayasan Saemaul Globalisasi Indonesia) dibantu Yayasan Panubulu yang bertugas sejak tahun 2015 dalam membantu menganalisa desa potensial yang aka dibina di Provinsi Yogyakarta. Yayasan Panubulu ini tidak lagi terlibat di dalam pendampingan pelaksanaan program Saemaul Undong hingga tahun 2018. Namun, untuk tahap awal Yayasan ini, menjadi mitra Saemaul Globalization Foundation (YSGF).

Yayasan Panubulu kemudian bersama Kementrian Desa membuat pelatihan tanggal 4-6 Desember untuk menampung aspirasi warga desa dan membuat pembinaan di dalam penyusunan Perdes (peraturan desa) yang kontekstual. Lalu, sebagai tindak lanjut dari pelatihan sebelumya, pelatihan pengenalan Saemaul Undong dan teknik pertanian mulai dilakukan. Melibatkan sejumlah pakar dari Saemaul Globalization Foundation(YSGF) Korea Selatan, pada 13-14 Januari 2016 di Universitas Gadjha Mada. Di tahap awal ini, ada 150 orang peserta yang mendapatkan pelatihan dari tiga desa; Desa Ponjong, Desa Bleberan, Desa Sumbermulyo. Namun di tahap awal, Desa Tanjung Wangi belum terlibat karena faktor administrasi (Saemaul Globalization Foundation Indonesia Office, 2015:1).

Di hari terakhir, tanggal 14 Januari 2016 untuk memperkuat legitimasi kerjasama antara Pemerintah Yogyakarta, dengan Saemaul Globalization Foundation (SGF) maka dibuat technical agreement mewakili Saemaul Globalization Foundation dengan BPPM (Badan Pemberdayaan Perempuan dan Masyarakat) Yogyakarta beserta BKPM (Badan Koordinasi Penanaman Modal) Yogyakarta dengan kesepakatan untuk membuat desa binaan, pelatihan, penyuluhan dan penyediaan anggaran dari masingmasing pihak yang terlibat. Dengan begitu, program Saemaul Undong mulai dilaksanakan. Dan secara khusus di dalam penelitian ini, akan diulas jalannya program Saemaul Undong di Desa Ponjong, Kabupaten Gunung Kidul, Yogyakarta. 
Rencana Pelaksanaan Program

Program Saemaul Undong, dilaksanakan selama lima tahun sejak tahun 2016-2020 di setiap desa binaan. Adapun perencanaan pembangunan yang dilaksanakan setiap tahunnya; Tahun 1, tujuan: Peningkatan kapasitas SDM dan penanaman motivasi, dengan aktivitas utama: Menggali potensi sumber daya dan membuat rencana jangka menengahpanjang untuk BUMDes.Tahun 2, tujuan: Penguatan kapasitas untuk operasional BUMDes dan pelatihan teknis terkait usaha desa. Aktivitas utama: Menjalankan usaha BUMDes (Pemda+Desa+Yayasan). Tahun 3, tujuan: Stabilitas operasional BUMDes, aktivitas utama: Pembentukan pakar BUMDes (teknis, produksi, penjualan dan manajemen). Tahun 4 dan 5, tujuan: Mencapai kemandirian BUMDes dan perkembangan berkesinambungan, dengan aktivitas utama: Peningkata keuntungan dan jumlah anggota (Buku Tahunan Program Pembangunan Saemaul, 2015/2016). Sehingga, setiap program yang akan dijalankan, khususnya di Desa Ponjong, Kabupaten Gunung Kidul, Yogyakarta akan dilakukan bertahap sesuai perencanaan pembangunan.

\section{Aktor Politik dalam Program Saemaul Undong}

YGSI (Yayasan Saemaul Globalisasi Indonesia) membentuk kantor perwakilan di masing-masing desa. Di Desa Ponjong, kantor perwakilannya disebut sebagai YGSI (Yayasan Saemaul Globalisasi Indonesia) Desa dengan 2 TKA (Tenaga Kerja Asing) berkewarganegaraan Korea Selatan yang siap mendampingi desa, satu orang

penerjemah

berkewarganegaraan Indonesia dan seorang fasilitator peternakan sapi (sesuai keperluan/potensi desa). Menurut hasil wawancara peneliti dengan kepala desa Ponjong, Kabupaten Gunung Kidul, Bapak Al Fauzi pada 13 April 2019 sebagai berikut;

"...Ya, ada dua orang Koordinator Lapangan dari Yayasan mereka digaji oleh pihak Korea sampai 2020, dengan 5 tahun masa tugas. YGSI di tingkat desa membuatlaporan program-program yang mereka lakukan ke pihak Korea, melalui kantor pusatnya yang ada di Yogya (YGSI). Yang dari Yogya nantinya melapor ke Koreanya (YSGF). Kalau terkait program itu ya betulbetul teliti, trasparan juga mereka. Ya, mereka yang mengawasi (jalannya program)..."

Sehingga, dua orang koordinator lapangan tersebut, dibantu seorang penerjemah ikut mengawasi jalannya program sesuai perencanaan sebelumnya agar terciptanya kemandirian desa. Kantor YGSI perwakilan desa, terpisah dengan Kantor Kepala Desa. Kantor YGSI berdampingan dengan kantor BUMDes (Badan Usaha Milik Desa) untuk mempermudah koordinasi karena titik temu kedua lembaga antara desa dengan BUMDes bertemu di program-program yang dikerjakan BUMDes. Sehingga, kinerja BUMDes dapat bergerak optimal dalam mengevaluasi dan memenuhi kebutuhan warga desa.Peran koordinator lapangan, menurut wawancara peneliti dengan salah seorang koordinator lapangan di Desa Ponjong, bernama Bapak You Jin, kewarga negaraan Korea Selatan yakni;

"...Peran koordinator lapangan disini tentu, sebagai jembatan (penghubung). Memang semua tim di Ponjong disini sama, Cuma ada fokusnya. Dari koordinator lapangan, akan bertemu pemerintah desa, juga bertemu warga. Nantinya bila warga punya usulan program apa, kami yang bantu berkomunikasi dengan pusat, nanti seperti apa hasilnya. Jadi, perannya itu untuk jembatan program dari warga mengusulkan apa, 
ngomong ke YGSI Desa, kami yang bantu ke pusat (YSGF).

Peran koordinator lapangan, membantu Desa dalam menganalisa potensinya. $\mathrm{Di}$ tahun pertama, kegiatan pelatihan-pelatihan pertanian, kewirausahaan, pemasaran dan kemasan produksi dan lain sebagainya dilakukan setiap tahunnya terhadap KWT (Kelompok Wanita Tani), Gapoktan (Gabungan Kelompok Tani), PKK (Pemberdayaan Kesejahteraan Keluarga), dan Karang Taruna banyak dilakukan. Selain itu, analisa potensi desa juga dilakukan untuk menambah unit usaha yang akan dikelola oleh BUMDes. Usulan pelaksanaan program tentu bermula dari usulan warga yang banyak disalurkan melalui rapat musyawarah desa setiap minggu dilakukan di hari Senin melibatkan pemerintah desa, BUMDes (Badan Usaha Milik Desa), warga dan YGSI (Yayasan Saemaul Globalisasi Indonesia) desa.Sehingga, di Desa Ponjong, terdapat dua unit usaha yang dikelola oleh BUMDes yaitu; kandang sapi komunal dan gedung serbaguna. Secara terperinci, kandang sapi komunal, merupakan peternakan sapi desa yang dikelola oleh para penggaduh (warga masyarakat) di mana sumber anggarannya diperoleh dari BUMDes (Badan Usaha Milik Desa), Pemerintah Desa dan YSGF (Yayasan Saemaul Globalization Foundation). Diharapkan, hasil peternakan sapi akan dibagi kepada warga berdasarkan hasil ternak dari sapi dan hasil untung dari penjualan sapi. Untuk prosedur pengobatan danteknis pemeliharaan sapi akan difasilitasi oleh YGSI (Yayasan Saemaul Globalisasi Indonesia) Desa dalam melatih dan mengundang narasumber. Kemudian, gedung serbaguna sering dijadikan sebagai tempat olahraga oleh para penduduk dan disewa oleh para warga untuk acara pernikahan atau kegiatan kemasyarakatan. Biaya penyewaan gedung akan dikelola oleh BUMDes dan dipakai bagi kepentingan desa. Begitu pula dengan Kepala Desa, selaku penanggung jawab jalannya pemerintahan desa juga berkewajiban mengawasi jalannya program desa, dan ikut mengawasi kinerja BUMDes dalam melaksanakan program Saemaul Undong bersama dengan YGSI (Yayasan Saemaul Globalisasi Indonesia) desa serta ikut bekerja sama dalam melaksanakan kemandirian desa di dalam ruang koordinasi masing-masing pihak. Sehingga, jika dicermati dengan saksama, aktor-aktor yang terlibat di dalam pelaksanaan program Saemaul Undong dari tingkat pusat hingga desa di Desa Ponjong, Kabupaten Gunung Kidul, Yogyakarta adalah sebagai berikut;

Tabel. 1 Aktor dan Peran Pelaksana Program Semaul Undong di Desa Ponjong, Kabupaten Gunung Kidul

\begin{tabular}{|c|c|c|}
\hline NO & Aktor & Peran \\
\hline 1. & $\begin{array}{l}\text { SGF/Provinsi } \\
\text { Gyeongsangbu } \\
\text { k-do }\end{array}$ & $\begin{array}{l}\text { Inisiator Program Saemaul } \\
\text { Undong dan Penyebarannya } \\
\text { ke berbagai negara } \\
\text { berkembang }\end{array}$ \\
\hline 2. & $\begin{array}{l}\text { Gubernur } \\
\text { Yogyakarta Sri } \\
\text { Sultan } \\
\text { Hamengkubuw } \\
\text { ono X }\end{array}$ & $\begin{array}{l}\text { Pemberi legitimasi } \\
\text { perealisasian program agar } \\
\text { terlaksana di beberapa desa } \\
\text { berdasarkan Mou dengan } \\
\text { sistem Sister Province }\end{array}$ \\
\hline 3. & $\begin{array}{l}\text { YSGI (Yayasan } \\
\text { Saemaul } \\
\text { Globalisasi } \\
\text { Indonesia) }\end{array}$ & $\begin{array}{l}\text { Kantor Perwakilan SGF di } \\
\text { Indonesia, menjembatani } \\
\text { hubungan antara desa } \\
\text { dengan pusat di Korea dan } \\
\text { mengawasi perealisasian } \\
\text { program di setiap desa. }\end{array}$ \\
\hline
\end{tabular}


Gultom, Y.W. Politik Pembangunan Desa dalam Program Saemaul Undong di Desa Ponjong

4. Yayasan Pihak yang menyeleksi Panubulu desa-desa potensial untuk

5. Kepala Desa dibina, (aktif hingga 2018)

Mengawasi pelaksanaan program di desa agar sesuai visi desa

6. YSGI

Perwakilan Desa/Koordina tor Lapangan beserta Tim

Fasilitator warga dalam perealisasian program.

Mengawasi jalannya

program.

Memperhatikan keperluan desa agar maksimal dalam menjalankan kegiatan

Saemaul Undong

7. Warga Pihak yang dibina dalam desa/PKK/Ga program Saemaul Undong poktan/KWT/ Pihak yang diharapkan Karang Taruna dan organisasi desa lainnya. dapat berperan aktif dalam memerhatikan keperluan desa dan memberi usulan program.

Pihak yang diharapkan dapat mengalami peningkatan ekonomi dari program Saemaul Undong.

Sumber: Hasil Observasi Pribadi

\section{Sistem Politik dalam Program Saemaul Undong}

Bentuk koordinasi lintas departemen menjadi ciri khas yang unik di dalam sistem yang dibangun saat pelaksanaan program Saemaul Undong berlangsung. Istilah yang digunakan yakni bernama "rapat jaringan". Rapat ini dibagi 3 jenis; Pertama, rapat jaringan di tingkat Provinsi Yogyakarta (pusat). Kedua, rapat jaringan di tingkat Kabupaten dan Ketiga, rapat jaringan di tingkat desa. Namun, karena desa yang diberdayakan hanya 4 desa sehingga rapat jaringan di tingkat kabupaten ditiadakan. Rapat jaringan di tingkat Provinsi, berlangsung sekali dalam satu bulan di Universitas Gadjha Mada; melibatkan Badan Pemberdayaan Perempuan dan Masyarakat, Perwakilan Kabupaten Bantul, akademisi UGM (Universitas Gadjha Mada), Yayasan Panubulu,
Kabupaten Bantul (PMD), Kabupaten Gunung Kidul (BPMPKB), UII dan SGF (Saemaul Globalization Found)/YGSI (Yayasa Saemaul Globalisasi Indonesia). Di tingkat desa, rapat jaringan ini melibatkan; BPMKB Gunung Kidul, Kelurahan, PKK/Gapoktan dan Koordinator lapangan (YGSI Desa).

Menurut hasil wawancara peneliti dengan staf YGSI Pusat ibu Ni Nyoman Resila Triwilasih pada 16 April 2019, gambaran koordinasi di dalam rapat jaringan sebagai berikut;

“...Kalau rapat jaringannya lebih kepada evaluasi sama rencana kedepan. Seharusnya kalau untuk rapat jaringan itu rencananya perbulan. Jadi persatu bulan sekali itu untuk mengetahui progres sama rencana kedepan seperti apa. Tapi kenyataannya itu kalau akhirakhir ini kurang terlaksana rapat jaringannya. Untuk rapat ini biasanya mengundang dari SGF Pusat, terus dari desa Pemdes, terus dari Kabupaten di undang juga, rapatnya di tiap desa. Jadi untuk undangannya dari YGSI yang ada di tiap desa lalu megundang yang di pusat, DPPM dan pemerintah daerahnya..."

YGSI pusat (di Gedung UGM) dan YGSI desa menjadi inisiator pertemuan satu bulan sekali, baik di tingkat provinsi maupun di tingkat desa untuk mengundang berbagai pihak seperti; narasumber yang diperlukan untuk merumuskan setiap solusi yang dibutuhkan dalam pelaksanaan berbagai program kedepan dan berbagai unsur yang terlibat di setiap pembahasan. Oleh karena model koordinasi yang rutin dalam bentuk sistem hirarkis dari pusat hingga ke desa, itu sebabnya tahun pertama pelaksanaan program Saemaul Undong di Desa Ponjong berupaya menjalankan penguatan pengorganisasian, pembinaan dan pelatihan warga desa bagi PKK, Gapoktan, KWT-Ponjong, dari setiap dusun serta penguatan pengorganisasian PKK. Di tahun pertama pelaksanaan kegiatan ini dilakukan pada 11-12 Februari dan 23- 
25 Februari. Beberapa bulan selanjutnya, pelatihan dimulai dengan pelatihan kewirausahaan, pertanian, pemasaran dan penguatan kelembagaan sehingga lembagalembaga di desa bergerak mandiri. Langkah ini menjadi cara penguatan aktor yang terlibat di dalam sistem koordinatif jalannya Program Saemaul
Undong di Desa Ponjong. Rincian Sistem yang dilaksanakan dapat dilihat pada bagan berikut ini: Bahwa, terdapat koordinasi di tingkat Provinsi (Local Governance DIY/dilaksanakan di Fakultas Filsafat UGM) dan di tingkat desa di Desa Ponjong.

\section{Bagan 1. Struktur Organisasi Local Governance Program Pembentukan Desa Percontohan Saemaul Indonesia Office.}

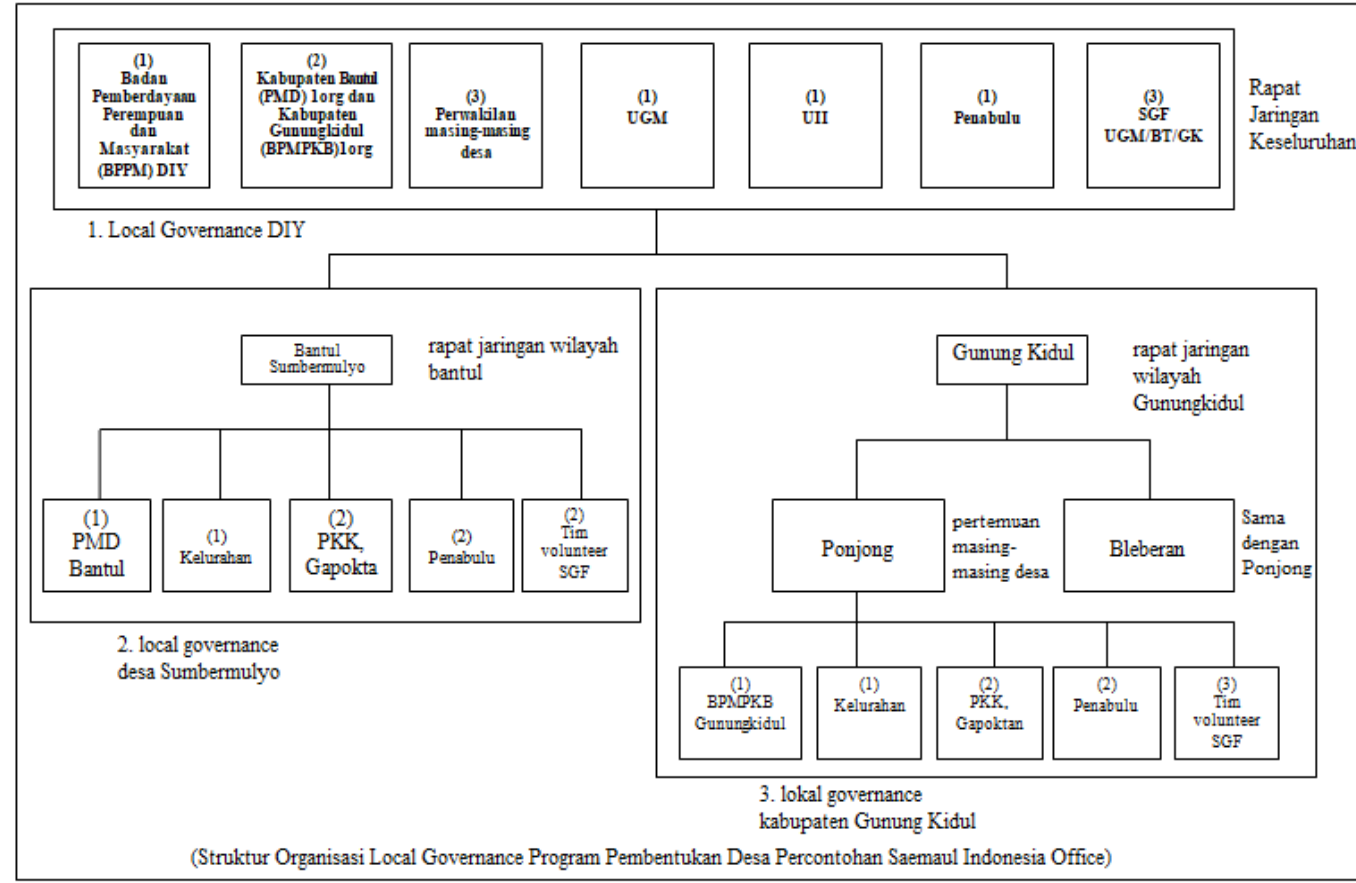

Sumber: BukuTahunan 2015/2016 Program Pembangunan DesaPercontohanSaemaul orang mewakili Gapoktan, PKK, KWT

Di desa Ponjong, di tahun ke-2, dan BUMDes Ponjong dalam

di tahun 2017, Desa mulai menjalankan fokus pembangunan desa dengan membahas rencana peternakan sapi komunal sebagai usaha warga dalam mengoptimalkan sumber daya pakan ternak di desa. Pada tanggal 27 Maret 2017 pertemuan antara BUMDes, Kepala Desa dan SGF Korea Selatan mengadakan pertemuan di Desa Ponjong untuk membahas pengadaan kandang sapi komunal. Kemudian, dilakukan pembinaan kepada 40

pembinaan dan penguatan pengorganisasian.

Di tahun yang sama, tanggal 4 Mei 2017, kembali disepakati pembuatan Gedung Serbaguna Saemaul oleh YGSI, BUMDes dan Pemerintah Desa. Pada tanggal 24 Mei 2017, dilakukan peletakan batu pertama dengan rencana 120 hari kerja penyelesaian gedung. Gedung Serbaguna Saemaul menjadi unit usaha yang dikelola oleh BUMDes 
dengan pengawasan dari YGSI Desa dan Kepala Desa. Apabila disetiap proses pelaksanaan kegiatan ditemukan kendala, maka di Desa Ponjong akan dilakukan rapat jaringan melibatkan YGSI, para penggaduh sapi, pengelola unit usaha, BUMDes dan perangkat desa setiap hari Senin di dalam musyawarah desa. Ada pula koordinasi sekali dalam sebulan melibatkan YGSI pusat dan dinas kabupaten terkait di tingkat desa. Sehingga, dapat ditelaah pula bahwa, Program Saemaul Undong di desa Ponjong memberikan pengaruh yang cukup signifikan, khusunya dalam penambahan produktivitas dan kinerja BUMDes (Badan Usaha Milik Desa). BUMDes (Badan Usaha Milik
Desa) memiliki tiga agenda penting pasca bekerja sama dengan YGSI (Yayasan Globalisasi Saemaul Indonesia) Desa diantaranya; Kandang Sapi Komunal dengan rincian 35 sapi dibeli dari modal YGSI dan sebanyak 6 ekor sapi dari dana BUMDes, kemudian program pengadaan Gedung Serbaguna dengan biaya total Rp. 1,29 Miliar dan program-program pelatihan yang dibutuhkan desa, sesuai hasil dari musyawarah desa yang diadakan setiap minggu di hari Senin. Secara sederhana, bagan dari rangkaian kinerja dalam pelaksanaan program Saemaul Undong di Desa Ponjong, Kabupaten Gunung Kidul, Yogyakarta adalah sebagai berikut;

\section{Bagan 2. Aktor dan Sistem di Dalam Program Saemaul Undong di Desa Ponjong Kabupaten Gunung Kidul Yogyakarta}

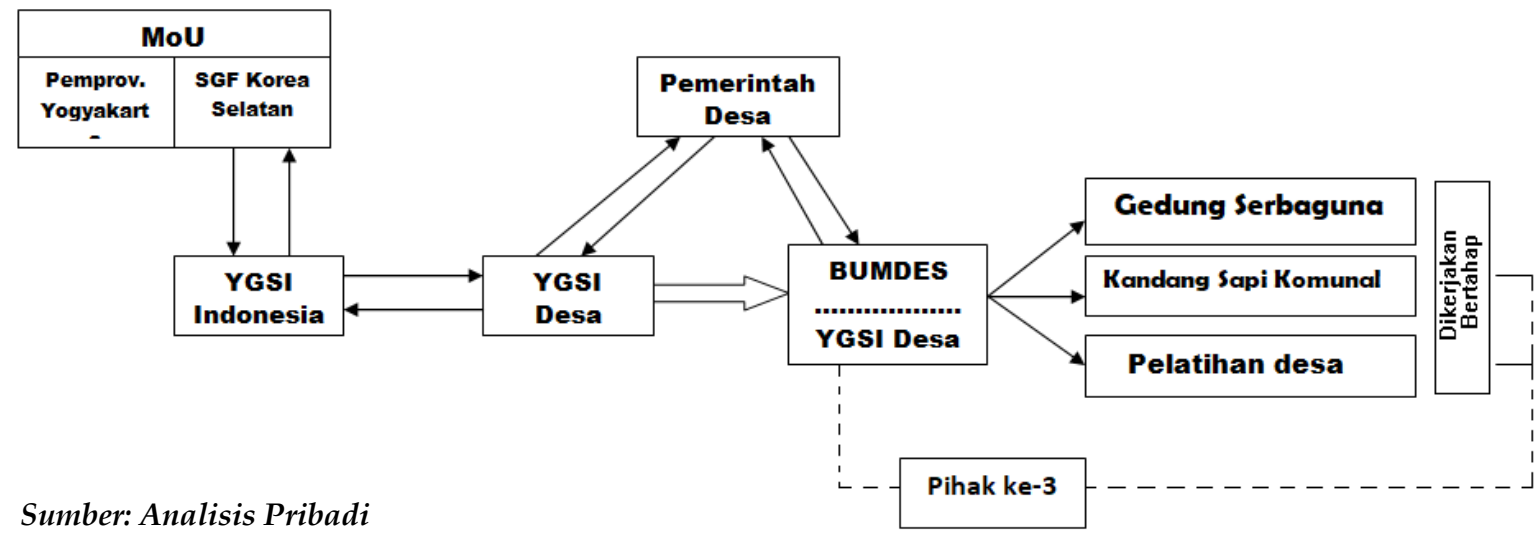


Dari bagan di atas, dapat diketahui, perencanaan Program Saemaul Undong bermula dari adanya Memorandum of Understanding (MoU) antara Pemerintah Provinsi Yogyakarta dengan Saemaul Globalization Found (SGF) Korea Selatan. Hasil dari kesepakatan tersebut menghasilkan Yayasan Globalisasi Saemaul Indonesia (YGSI) berkantor di Fakultas Filsafat UGM, kemudian YGSI mendampingi beberapa desa, khususnya di Desa Ponjong, Kabupaten Gunung Kidul, Yogyakarta. YGSI kemudian membuat kantor perwakilan, yang disebut sebagai YGSI Desa. YGSI desa bekerja sama dengan Pemerintah Desa, kemudian YGSI Desa yang terdiri dari dua orang koordinator lapangan, seorang penterjemah dan seorang fasilitator peternakan sapi (sesuai keperluan desa) turut berperan dalam peningkatan kapasitas dan kemampuan BUMDes (Badan Usaha Milik Desa) di Desa Ponjong. YGSI desa menjadi pihak ketiga, yang turut mengoptimalkan peran BUMDes dan dihasilkanlah beberapa unit usaha yang dikelola BUMDes seperti membuat pelatihan dan pemberdayaan rutin, kemudian kandang sapi komunal dan gedung serbaguna.

\section{Rincian Kegiatan Berdasarkan Tahun Pelaksanaan}

Jika dicermati, berdasarkan tahun pelaksanaan program Saemaul Undong di Desa Ponjong, Kabupaten Gunung Kidul, Yogyakarta maka kegiatan yang telah dilakukan adalah sebagai berikut; Tahun pertama jalannya program Saemaul Undong dimulai di tahun 2016. Di tahun ini, program-program pelatihan banyak dilakukan, serta upaya penguatan organisasi lantaran fokus tahun pertama program yakni menggali potensi sumber daya dan membuat rencana jangka menengah dan jangka panjang untuk BUMDes di tahun 2016. Ragam jenis pelatihan yang dilakukan di tahun ini seperti; Pertemuan Rutin PKK dan Gapoktan untuk pemotivasian semangat Saemaul, pengenalan nilai-nilai luhur desa, serta membahas rencana pengoptimalan desa. Kegiatan ini mulai rutin dilakukan di bulan Februari 2016. Kemudian, terdapat pelatihan dan penguatan kelompok Gapoktan, KWT-Ponjong (11-12 Februari 2016) dan Pelatihan Penguatan Kelompok PKK (23-25 Februari 2016), Pelatihan Pengolahan Pisang (29-31 Maret 2016), Pelatihan Pengolahan Limbah Pertanian Gapoktan (11-12 April 2016), Pelatihan Penguatan Kelembagaan Desa (18-19 Mei 2016), Pelatihan Penguatan Kapasitas RT dan RW (2021 Juli 2016), Pelatihan Pembuatan Demonstrasi Plot dan Pemanfaatan Lahan (8-9 Agustus 2016), Pelatihan Marketing Usaha Kecil dan Menengah (8 September), Sekolah Lapangan Tiga (Dalam Pemilihan Bibit Pertanian Unggul) (17 Oktober 2016) (Saemaul Globalization Foundation Indonesia Office, 2016).

Tahun Kedua jalannya program Saemaul Undong, dimulai di tahun 2017 difokuskan untuk Penguatan Kapasitas Operasional BUMDes dan Pelatihan Teknis Usaha Desa 2017. Di tahun ini, mulai dibahas produk unggulan yang akan dikelola BUMDes berdasarkan potensi desa dengan tetap membuat pelatihan bagi warga desa. Tanggal 27-29 Maret 2017, dilakukan pelatihan peternakan sapi 
bagi 40 orang perwakilan Gapoktan, KWT, PKK dan BUMDes Ponjong. Pembahasan dan Peletakan batu pertama Gedung Serbaguna (4-24 Mei 2017), Perbaikan Fasilitas Pendidikan Dasar Usia Dini Desa Ponjong dari tim YGSI kepada 6 TK (Taman Kanakkanak), Kegiatan Relawan Mahasiswa Saemaul dari Korea Selatan dari Kyungwoon University sebanyak 25 orang melakukan pengabdian pada 18-24 Juli 2017 untuk saling membantu, bertukar kebudayaan dan perbaikan fasilitas sekolah, penanaman pohon dan pertunjukan seni. Di tahun ini juga dilakukan peresmian Kandang Sapi Komunal (11 September 2017), Peresmian Gedung Serbaguna Saemaul Desa Ponjong (17 Oktober 2017) dan Pembelian bibit sapi sebanyak 41 Sapi di tanggal 15-16 Desember $2017 \quad$ (Saemaul Globalization Foundation Indonesia Office, 2017).

Tahun Ketiga, fokus program yakni mengupayakan stabilitas operasional BUMDes di tahun 2018 sesuai produk unggulan yang diprioritaska warga desa. Beberapa agenda yang terlaksana di tahun 2018 seperti; Penimbangan berat sapi di kandang sapi komunal Desa Ponjong, Pelatihan Saemaul: Memajukan Desa Pertanian dan pengelolaan desa wisata, pembangunan Greenhouse percontohan Saemaul di Desa Ponjong, Kunjungan Pemerintah Provinsi Gyeong Sangbuk-Do ke Desa Ponjong diwakili 12 Pegawai Negeri Sipil Gyeong Sangbuk-do (8 Mei 2018). Penyuluhan ternak dari Puskeswan Karangmojo (14 Agustus), Sosialisasi KWT dan Pertemuan Rutin Penggaduh (13 September), Penyuluhan Puskeswan (Petugas Kesehata Hewan) Karangmojo. Rapat koordinasi perbaikan sistem pemeliharaan sapi, MONEV (Monitoring dan Evaluasi) BPPM DIY ke Desa Percontohan Saemaul. Agenda rutin kelompok ternak kandang sapi komunal (September Oktober 2018) (Saemaul Globalization Foundation Indonesia Office, 2018). Di tahun Keempat dan Kelima, fokus program Saemaul Undong mengupayakan persiapan kemandirian desa, stabilitas operasional BUMDes (Badan Usaha Milik Desa) dan kemandirian BUMDes (Badan Usaha Milik Desa) dan perkembangan yang berkesinambungan serta persiapan kemandirian warga desa dalam berusaha.

\section{KESIMPULAN}

Program Saemaul Undong di

Desa Ponjong, Kabupaten Gunung Kidul, Yogyakarta menjadi usulan model dalam pengimplementasian pasal 91 Undang-Undang Desa No. 6 tahun 2014, bahwa adanya kerjasama desa lintas desa, atau dalam hal ini kerjasama desa dengan pihak ketiga. Pengembangan yang dilakukan di Desa Ponjong sifatnya bertahap, dimulai dari analisa potensi desa, penguatan pengorganisasian desa dan pengembangan potensi dan kapasitas masyarakat desa. Kemudian, pengoptimalan BUMDes dengan berkoordinasi dengan pihak ke-tiga (Kampus/LSM-Lembaga Swadaya Masyarakat) bisa menjadi sarana untuk memperkuat usaha lokalnya masing-masing. Disamping itu, koordinasi antar lembaga di dalam rapat jaringan untuk membahas setiap persoalan, dan menemukan solusi terbaik bisa menjadi usulan terhadap lemahnya 
pembangunan desa, dengan tidak terlalu lama mengabaikan persoalan desa, namun segera berkoordinasi menuntaskan persoalan desa. Berbagai strategi yang dilakukan dalam pembangunan desa di Desa Ponjong dalam menjalankan Program Saemaul Undong boleh menjadi model yang bisa dipelajari bersama demi kemajuan kolektif desa.

\section{DAFTAR PUSTAKA}

Gultom, Yohansen W. 2019. Relevansi Politik Pembangunan Saemaul Undong di Desa Ponjong Kabupaten Guung Kidul Yogyakarta Terhadap Pembangunan Desa di Desa Sipira Kabupaten Samosir Pasca UU Desa No. 6 Tahun 2014. Medan: Departemen Ilmu Politik Fakultas Ilmu Sosial dan Ilmu Politik Universitas Sumatera Utara.

Gultom, Yohansen W. 2021. Pola Politik Pembangunan Desa di Indonesia Pasca Hadirnya UU Desa No. 6 Tahun 2014 dan Politik Pembangunan Saemaul Undong di Korea Selatan Era Park Chung Hee (1963-1979). Politea Jurnal Ilmu Politik, 13 (2), 16-28. Diakses dari:https://talenta.usu.ac.id/poli teia/article/view/6187/4008.

Kyungwon University Saemaul Academy. (2008). Korea Selatan. Panduan Saemaul Undong pada Abad ke-21.

Royani, Ama Heidi. 2018. Skripsi penelitian dengan judul, Implementasi Model Pemberdayaan Saemaul Undong di Desa Ponjong Kecamatan Ponjong Kabupaten Gunung Kidul. Yogyakarta: Universitas Gajah Mada.
Saemaul Globalization Foundation Indonesia Office. 2015. Laporan Berkala Pembentukan Desa Percontohan Saemaul Bulan Januari 2015 - Desember 2015. Yogyakarta: YGSI.

Saemaul Globalization Foundation Indonesia Office. 2016. Laporan Berkala Pembentukan Desa Percontohan Saemaul Bulan Januari 2016 - Desember 2016. Yogyakarta: YGSI.

Saemaul Globalization Foundation Indonesia Office. 2017. Laporan Berkala Pembentukan Desa Percontohan Saemaul Bulan Januari 2017 - Desember 2017. Yogyakarta: YGSI.

Saemaul Globalization Foundation Indonesia Office. 2018. Laporan Berkala Pembentukan Desa Percontohan Saemaul Bulan Januari 2018 - Desember 2018. Yogyakarta: YGSI.

Saemaul Globalization Foundation Indonesia Office. 2019. Laporan Berkala Pembentukan Desa Percontohan Saemaul Bulan Januari 2019 - Desember 2019. Yogyakarta: YGSI.

Primus, Josephus dalam Indonesia dan Korea Sepakat Penerapan Konsep Saemaul Undongdiakses dari: https:// money.kompas.com/read /2015/11/28/160025126/Indones ia.dan.Korea.Sepakati.Penerapan. Konsep.Saemaul.Undong pada 21 September 2019 pukul 09.25 WIB. 